\section{LUPUS SCIENCE\& MEDICINE}

\title{
The Care-coordination Approach to Learning Lupus Self-Management: a patient navigator intervention for systemic lupus inpatients
}

\author{
Ashley A White, ${ }^{1}$ Aissatou Ba, ${ }^{1}$ Trevor Daniel Faith, ${ }^{2}$ Viswanathan Ramakrishnan, ${ }^{1}$ \\ Clara L Dismuke-Greer, ${ }^{3} \mathrm{Jim}$ C Oates (D) , ${ }^{4,5}$ Edith Marie Williams (D) ${ }^{1}$
}

To cite: White AA, Ba A, Faith TD, et al. The Carecoordination Approach to Learning Lupus SelfManagement: a patient navigator intervention for systemic lupus inpatients. Lupus Science \& Medicine 2021:8:e000482. doi:10.1136/ lupus-2021-000482

- Additional supplemental material is published online only. To view, please visit the journal online (http://dx.doi.org/10. 1136/lupus-2021-000482).

Received 1 February 2021 Revised 12 April 2021 Accepted 16 April 2021
Check for updates

(c) Author(s) (or their employer(s)) 2021. Re-use permitted under CC BY-NC. No commercial re-use. See rights and permissions. Published by BMJ.

For numbered affiliations see end of article.

Correspondence to

Dr Edith Marie Williams; wiled@ musc.edu

\begin{abstract}
Objective The Care-coordination Approach to Learning Lupus Self-Management (CALLS) study was designed to improve SLE disease self-management. This study aims to assess the benefits of the intervention compared with existing lupus care.

Methods Participants were randomly assigned to participate in 12-weekly phone sessions with the patient navigator that included structured educational content, care coordination and patient-centred support services, or a usual care control condition. Validated measures of health literacy, self-efficacy, patient activation and disease activity were collected. We used least squares means and linear mixed-effects regression models for each outcome variable to assess the changes in outcome, from baseline to postintervention and to estimate the difference in these changes between the intervention and control group.

Results Thirty participants were enrolled and 14 were randomised to the treatment group. For perceived lupus self-efficacy, there was a significant increase in mean score for the intervention group, but not for the control group. With regard to disease activity, the experimental group experienced a slight decrease in mean flare score in the previous 3 months, whereas the control group experienced a slight increase, but this finding did not reach statistical significance. Trends were similar in selfreported global disease activity, but none of the findings were significant. Health literacy and patient activation

\section{Key messages}

What is already known about this subject?

- The patient navigator role has become more prominent in recent years as an important means of achieving significant outcomes for patients, their families and the larger health system.

What does this study add?

- Overall, the CALLS intervention appeared to improve patient activation and self-efficacy; and decreased the occurrence of lupus flares, and global ratings of lupus disease activity, although findings did not reach statistical significance.

- The results of this study demonstrate the potential efficacy of SLE-specific patient navigation and the potential for individually tailored educational content delivered in weekly phones sessions to improve SLE disease self-management.

How might this impact on clinical practice or future developments?

- Having a lay patient navigator on the healthcare team could sustain the benefits of a time-limited intervention designed to provide modelling and reinforcement by peers to encourage other patients with SLE to engage in activities that promote disease self-management.
\end{abstract} measure scores remained largely unchanged throughout the study for the two groups.

Conclusion These findings suggest that the CALLS intervention may work to improve aspects of SLE disease self-management. Future research will be needed to validate these findings long-term.

Trial registration number NCT04400240.

\section{INTRODUCTION}

SLE is a chronic multisystem autoimmune disease with various manifestations inclusive of acute periodic flare-ups of symptoms impacting various organ systems and resulting in potentially life-threatening complications. Annual healthcare utilisation costs associated with SLE flares are estimated to be US $\$ 10$
000-US $\$ 50000$ more than costs for patients without SLE. ${ }^{2}$ The majority of these costs are generated from inpatient hospitalisations, long-term disease management, disease severity, pharmacy services, poor physical and mental health and low education and employment levels. ${ }^{3-5}$ Patients with SLE are also impacted by significant functional and emotional challenges resulting from SLE symptoms, side effects and complications, including anxiety, depression, mood disorders and decreased health-related quality of life (HRQOL), leading to additional healthcare service utilisation and increased costs. ${ }^{67}$ 


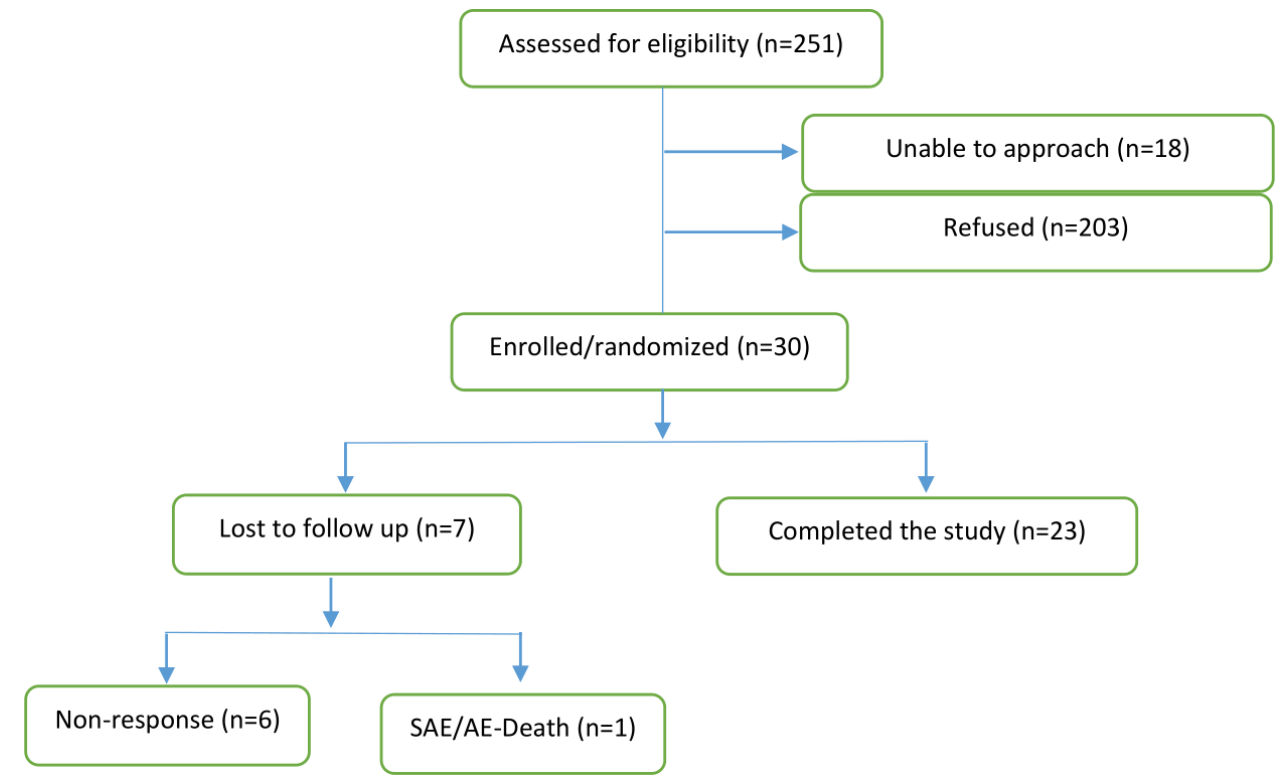

Figure 1 Flow diagram for Care-coordination Approach to Learning Lupus Self-Management recruitment. SAE/AE, serious adverse event/adverse event.

In African-Americans in the USA, SLE has a twofold to fourfold increase in frequency, severity, risk of development at an earlier age and SLE-related disease activity, damage and mortality compared with Caucasians. ${ }^{8}$ Specifically, in the USA the highest SLE morbidity and mortality rates are among African-American women. ${ }^{9}$ Current scientific literature indicates that adequate social support could serve as a protective factor because it allows patients and their families to navigate and adequately use the health systems. ${ }^{10}$ While evidence-based self-management interventions for patients with lupus that targeted both social support and health education have reduced pain, improved function and delayed disability among patients with SLE, ${ }^{2}$ African-Americans and women are still disproportionately impacted by SLE. ${ }^{11}$ The prevalence of SLE in the USA ranges from 20 to 150 cases per 100000 . In AfricanAmerican women, prevalence rates drastically increase to 406 cases per 100000 compared with 164 cases per 100000 for white women. ${ }^{12}$ This disproportionate impact of SLE highlights the need for interventions to address the unique needs of African-American women with lupus. An intervention that improves the learning of self-management skills measured by patient activation, self-efficacy and disease activity is important because of their application to clinical outcomes, hospitalisations and SLE disease disparities experienced by the African-American community. Patient activation measures one's knowledge and skills to manage their health and healthcare ${ }^{13}$ such as with food choices and treatment adherence. ${ }^{14}$ Treatment adherence, especially among African-American Medicaid beneficiaries with lupus is often low ${ }^{15}$ and depressive symptoms have been associated with low medication adherence. ${ }^{16}$ African-American women with depressive symptoms have been shown to have increased organ damage compared with those without depression. ${ }^{17}$ Self-efficacy pertaining to coping skills helps manage psychosocial stressors such as depression. ${ }^{18}$ Increased feelings of helplessness and abnormal illness-related behaviours have been associated with increased disease activity, which was found to be a predictor of early mortality. ${ }^{19}$

The patient navigator role has become more prominent in recent years as an important means of achieving significant positive outcomes for patients, their families and the larger health system. These outcomes include increased patient satisfaction with healthcare services provided, ${ }^{20}$ an increase in patient access to healthcare services $^{21}$ and a decrease in the hospital length of stay and unplanned readmission. ${ }^{22}$ Research has shown that the most effective care coordination interventions are focused on providing holistic, relationship-based care. ${ }^{23-26}$ For these reasons, using this interventional approach for SLE is ideal because mentoring could establish trust and in turn decrease disparities in SLE healthcare outcomes. Having a lay patient navigator on the healthcare team could sustain the benefits of a time-limited intervention designed to provide modelling and reinforcement to encourage patients with SLE to engage in activities that promote disease self-management. Therefore, the Care-coordination Approach to Learning Lupus SelfManagement (CALLS) study was designed to examine whether structured education, individualised assistance and encouragement from a lay patient navigator improves SLE patient disease self-management using indicators of health literacy, lupus self-efficacy, patient activation and disease activity. Compared with treatment as usual, we hypothesised that a brief regular telephone navigation intervention would contribute to improved health outcomes.

\section{METHODS}

The CALLS study was a randomised controlled trial (see online supplemental files 1 and 2) of a patient navigator 


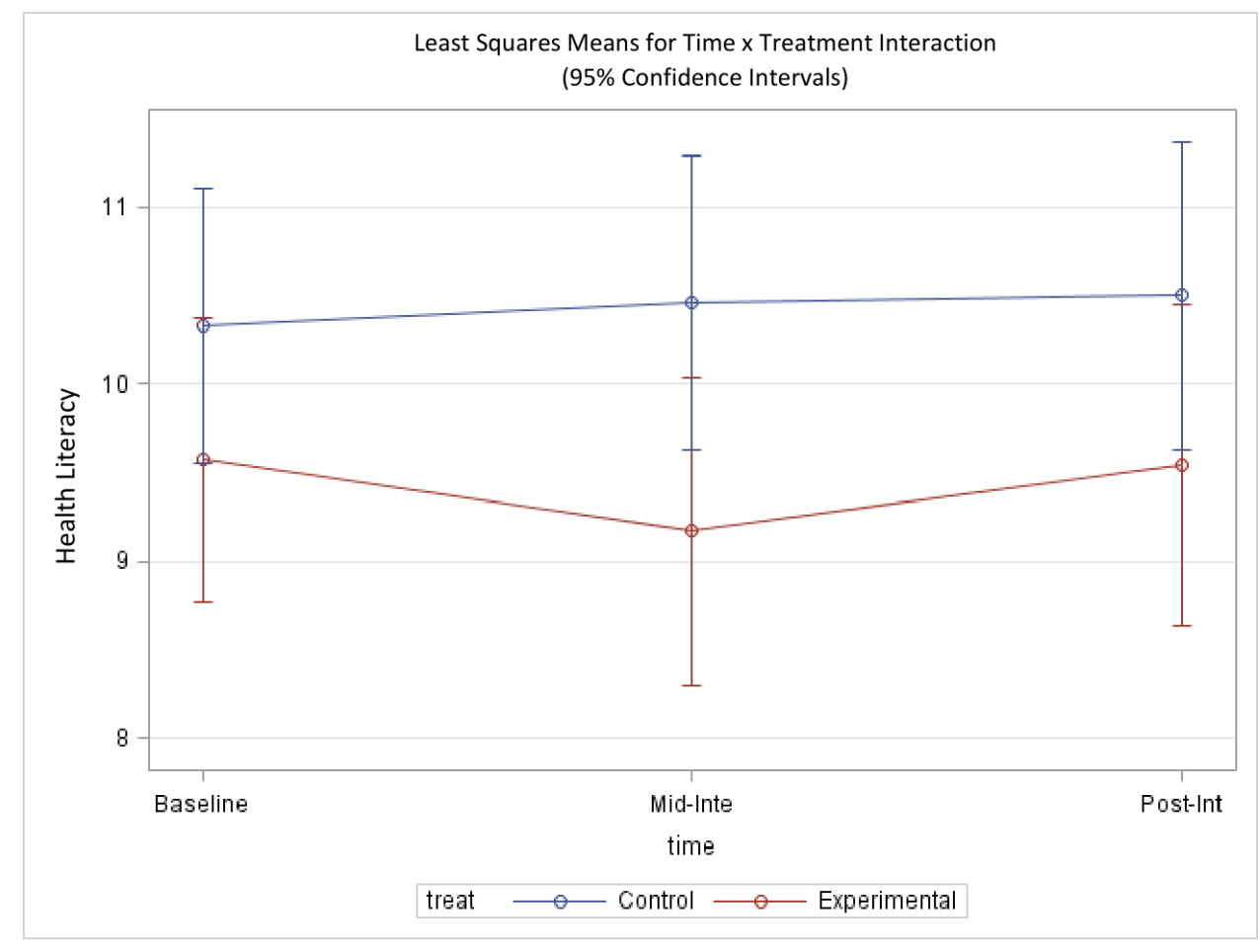

$\begin{array}{lll}\text { P-values } & & \\ \text { Difference between groups } 0.82 & \text { Baseline to Mid-Intervention } & \text { Baseline to Post-Intervention } \\ \text { Control } & 0.82 & 0.77 \\ \text { Experimental } & 0.49 & 0.96\end{array}$

Figure 2 Mean score change of health literacy over time.

intervention for patients with SLE at the Medical University of South Carolina (MUSC). Consenting patients were randomised into intervention and control groups. Intervention participants completed questionnaires and 12 weekly phone sessions, and controls completed questionnaires only. Questionnaires were collected at baseline, mid-intervention (6 weeks postenrolment) and postintervention (12 weeks postenrolment). With each questionnaire completion participants received a US $\$ 50$ payment. Data were entered into a Research Electronic Capture database, and phone sessions were audio recorded and uploaded into a cloud-based storage system approved for data storage at MUSC (MUSC Box Cloud).

\section{Participants}

Recruitment efforts for the current study were limited to inpatient admissions since hospital admission could indicate failed disease self-management. Eligible participants were identified using the EPIC system, MUSC's electronic health record. A report was generated daily during the 1-year enrolment period from February 2018 to February 2019. The report returned inpatients currently admitted in the MUSC Health centre. Inclusion criteria included a diagnosis of SLE in the medical record, being at least 18 years of age, ability to communicate in English and possessing an active phone line. Patients with cognitive impairments, documented alcohol or drug abuse disorders and terminal illnesses with a life expectancy
$<6$ months were excluded from participation. A chart review was used to confirm clinical eligibility criteria while communication capacity and possession of a phone line were confirmed before enrolment. Potential participants were solicited during their hospital admission, when possible and appropriate. If they had previously consented to contact for research, they were approached directly. If not, materials were shared with their attending physician(s) to pass along during their admission. All patients were approached in the hospital and the intervention was rolled out after discharge. If patients were not approachable during their admission, they were excluded from recruitment. Participants were randomised on consent, and their first questionnaire and call or questionnaire only was scheduled 1-2 weeks after their discharge.

\section{Patient navigator}

Participants who were assigned to the treatment arm of the study participated in weekly phone sessions with the patient navigator. The patient navigator (AW) was a PhD student at MUSC holding a master's of public health degree in health education and health promotion. Weekly sessions with the patient navigator included structured educational content as well as care coordination and patient-centred support services. Structured educational material was adapted from the Peer Approaches to Lupus Self-management study ${ }^{27} 28$ and covered a myriad of topic areas including medication adherence, 


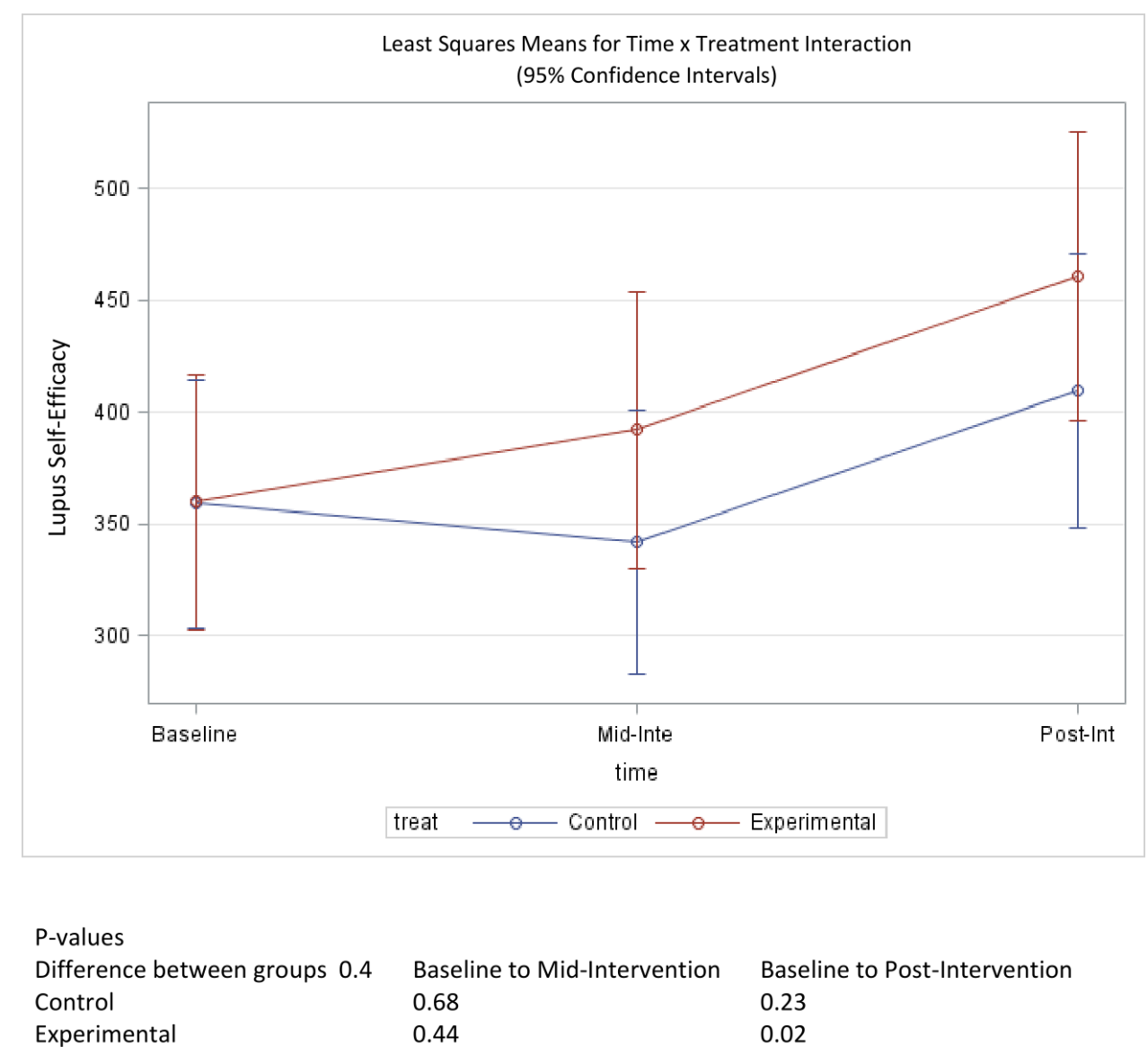

Figure 3 Mean score change of self-efficacy over time.

communication with providers, patient engagement, recognising and treating depression, overcoming socioeconomic barriers to care, social support networks, appointment/lab adherence and transportation. The patient navigator responded to individual patient needs by tailoring intervention content to personal considerations while providing understandable health education that was intended to lessen fears of SLE diagnosis and treatment.

Prior to implementing the intervention, the patient navigator underwent training to ensure treatment fidelity. This included 12 hours of education with rheumatologists at MUSC and a week of role-playing practice with the principal investigator to provide background knowledge on SLE and experience in sensitive interactions with prospective participants. Finally, the navigator was provided with a written manual presenting all intervention material in detail for their ongoing reference. ${ }^{2728}$

\section{Intervention}

After completing the baseline questionnaire, participants randomised into the intervention group scheduled their first phone call. The intervention guide was sent to participants in increments by post mail or electronically. After the first session, each sequential session began with a check-in that allowed the participant to reflect on the topic and strategies discussed from the previous session. Throughout each session the patient navigator discussed content in a conversational style and encouraged questions from the participants. Each session ended with the participant deciding on action items to pursue relevant to the topic discussed and confirmed the next call. Some participants kept a consistent day and time for their calls, while others changed weekly depending on their availability.

The intervention guide was divided into 12 sessions. Session 1 covered introductions and programme overview. Session 2 covered strengthening the participants control over their lupus through lifestyle behaviours. Session 3 covered medication and different complementary medicine treatments related to lupus. Session 4 covered healthy communication with family, friends and health professionals. Session 5 covered nutrition and healthy eating. Session 6 covered recognising stress and ways to relax. Session 7 covered mentally and emotionally coping with lupus pain. Session 8 covered how lupus affects the physical appearance of the body. Session 9 covered the complexities of living with lupus. Session 10 covered managing mood changes when experiencing lupus pain. Session 11 covered having a healthy sexual relationship while living with lupus. Session 12 covered ways to successfully live with lupus by identifying core values and reviewing strategies developed from the previous sessions. After the completion of the last session, participants did an exit interview 


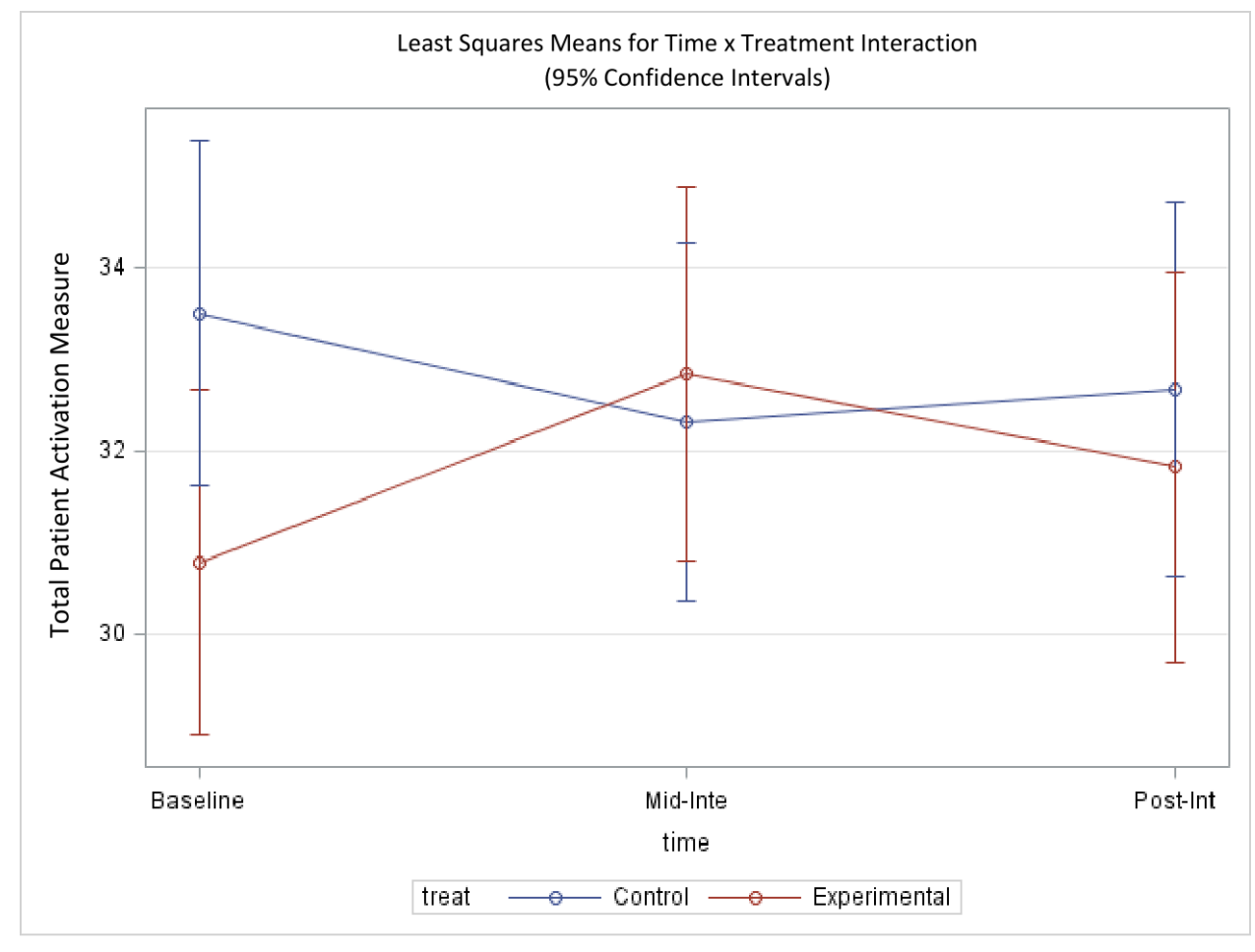

$\begin{array}{lll}\text { P-values } & & \\ \text { Difference between groups } 0.35 & \text { Baseline to Mid-Intervention } & \text { Baseline to Post-Intervention } \\ \text { Control } & 0.38 & 0.55 \\ \text { Experimental } & 0.14 & 0.47\end{array}$

Figure 4 Mean score change of patient activation over time.

with the PI to discuss their experience with the patient navigator.

\section{Outcome measures}

Outcomes were assessed using previously validated survey instruments grounded in well-established theoretical frameworks and included health literacy, lupus self-efficacy, patient activation and disease activity. All participants were asked to complete questionnaires at baseline (postenrolment, pre-intervention), 6 weeks and 12 weeks (following the final session for participants in the treatment group). Health literacy was assessed at each time point using the Chew Health Literacy Scale-a brief three-question assessment of self-reported health literacy. ${ }^{29}$ This scale is ordinal and includes 5-point Likert items ranging from 'none of the time' to 'all of the time'. Participants were asked to self-report their perceived self-efficacy in managing their SLE symptoms using the Lupus Self-Efficacy Scale. ${ }^{3031}$ This scale was ordinal and consisted of integers ranging from 0 to indicate 'very uncertain' to 100 to indicate 'very certain'. While patient activation, a measure assessing active participation in their care and disease management, was captured with the patient activation measure (PAM) ${ }^{13}$ This scale is ordinal and includes 4-point Likert items ranging from 'disagree strongly' to 'agree strongly' and the option of 'not applicable (N/A)'. Self-reported disease activity was captured using the Systemic Lupus Activity Questionnaire (SLAQ). The SLAQ was developed as tool to determine the severity of SLE symptom and flare activity in patients with SLE without the need for a physician assessment. ${ }^{32}$ This scale is ordinal and includes 4-point Likert items ranging from 'no flare' to 'severe flare'. Other variables were measured by previously validated items from the 2002 National Health Interview Survey to capture age, marital status, education, household income and health insurance; the Patient Health Questionnaire-9, which scores each of the nine Diagnostic and Statistical Manual of Mental Disorders, fourth edition criteria for depression ${ }^{33}{ }^{34}$; the 7-item General Anxiety Disorder scale ${ }^{35}$ and the Lupus Quality of Life Questionnaire, ${ }^{36-38}$ which incorporates the Medical Outcomes Study Short Form 36 Health Survey and the Functional Assessment of Chronic Illness TherapyFatigue. To assess for differences in outcome expectancy, a modified treatment credibility scale developed by Borkovec and Nau was used. Four of the questions were used for this study, with 10-point Likert scales. These include questions regarding how logical the treatment seemed, how confident participants were about treatment and their expectancy of success. ${ }^{39}$ Satisfaction with care among participants in the intervention group was measured with a validated general scale to measure satisfaction/dissatisfaction with 


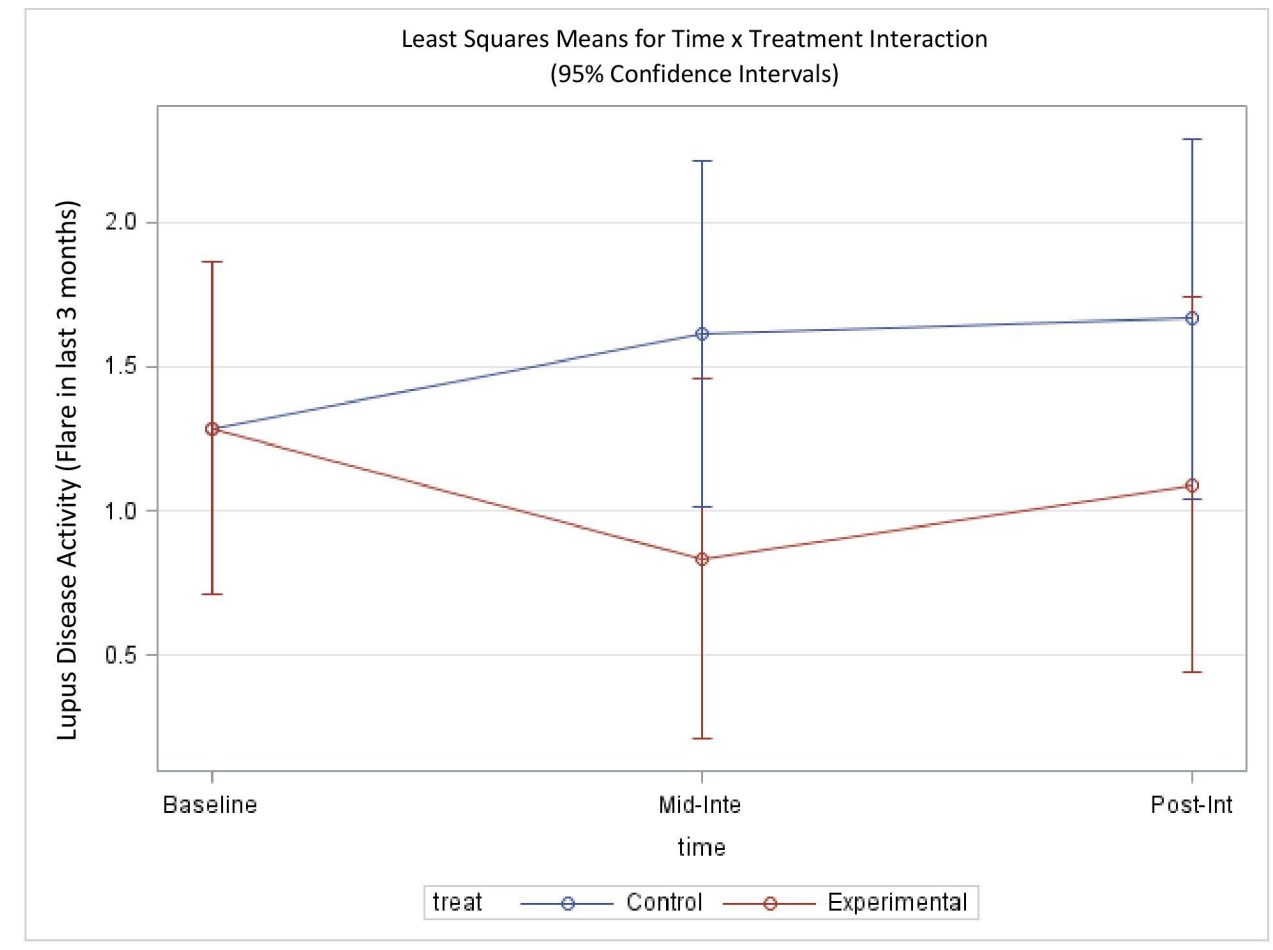

$\begin{array}{lll}\text { P-values } & & \\ \text { Difference between groups } 0.35 & \text { Baseline to Mid-Intervention } & \text { Baseline to Post-Intervention } \\ \text { Control } & 0.43 & 0.29 \\ \text { Experimental } & 0.37 & 0.66\end{array}$

Figure 5 Mean score change of disease exacerbations (flares) over time.

healthcare. The two-item scale ranges from 1 (strongly agree) to 5 (strongly disagree). ${ }^{40}$

\section{Statistical methods}

Sample size was initially based on the outcome of change in HRQOL between baseline and 12 months postintervention, but this outcome is not presented. Data presented for the four outcomes of self-efficacy, patient activation, health literacy and disease activity are the result of post hoc analyses. The minimum sample size was based on detecting a clinically meaningful difference of 0.35 SD units (medium effect) based on prior studies. ${ }^{1732}$ Participants were randomised using a web-based block randomization procedure to assure equal sample sizes in both arms. Using a block size of 3, participants were assigned to the appropriate treatment condition as they enrolled in the study until the block was completed. Participants remained blinded to group allocation until after the completion of the baseline assessment. The only members of the research team who were aware of randomisation assignments were the research coordinator and the statistical analyst in charge of randomisation.

Descriptive data on outcomes measures were calculated using SAS V.9.4 and R Studio V.1.2.1335, only examining those individuals with complete data. Mean scores are reported for the treatment and control cohorts. We used least squares means and contrast statements for each outcome variable to compare the changes in outcome, from baseline to postintervention. Linear mixed-effects regression models were calculated to estimate the difference in the change from baseline to postintervention between the intervention and control groups in each of the outcomes of interest. Corresponding 95\% CIs were determined for the estimates of the difference in outcome means (effect sizes) between and within treatment group.

\section{RESULTS}

Thirty participants were enrolled and 14 participants (46.7\%) were randomised to the treatment group. Figure 1 shows that seven (23.3\%) were lost to follow-up during the course of the study. Of these participants, three were in the treatment group and four were in the control group. One participant failed to start after consent was given and six of them completed the baseline questionnaire; of which one also competed the midintervention questionnaire. The dropout was differential in that one participant died and the other six refused to return communication. Participants' ages varied significantly with the majority $(62 \%)$ of participants falling between the ages of 25 and 54 years. Most participants reported having completed a high school education $(93.1 \%)$, being unmarried $(55.2 \%)$, either unemployed or receiving disability benefits $(55.2 \%)$ and covered with a private health insurance policy $(63.3 \%)$. Notably, a large portion $(35.7 \%)$ of participants indicated that their 
yearly household income was $<$ US $\$ 15000$. Detailed demographic information is presented in table 1 . Analyses were performed on complete data from 11 participants in the intervention group and 12 participants in the control group. The average number of sessions completed was 11.58 , and the average duration of phone sessions was $36.16 \mathrm{~min}$.

\section{Health literacy}

Average baseline health literacy for the CALLS intervention group was 9.57 out of 15 possible points, whereas the self-reported health literacy score for the control group was 10.3 (table 1). The treatment group experienced a decrease in health literacy at the midpoint assessment, but the average health literacy score rebounded to 9.55 at postintervention. Similarly, the control group's health literacy score remained largely unchanged with a selfreported average health literacy score of 10.5 at the postintervention time point (figure 2). Changes were not statistically significant for either group, with $\mathrm{p}$ values of 0.96 and 0.77 for the treatment and control groups, respectively. Moreover, between-group comparisons did not reveal any significant differences in pre-post changes to health literacy $(\mathrm{p}=0.82)$.

\section{Lupus self-efficacy}

At baseline, perceived lupus self-efficacy was nearly identical in both groups (table 1). The treatment group reported a mean score of 359.86 while the control group's mean score was 358.87 out of 600 possible points. An upwards trend was observed throughout the study for the treatment group, which reported a mean score of 461.09 postintervention. This change represented a statistically significant improvement in lupus self-efficacy $(p=0.02)$. Conversely, the mean scores dropped for the control group at midpoint, to 341.92 , but increased to 409.67 by the end of the study (figure 3 ). The change observed in the control group did not reach statistical significance $(\mathrm{p}=0.23)$. A comparison of the pre-post score change between groups did not indicate that the treatment group experienced a significantly greater increase in self-efficacy scores $(\mathrm{p}=0.4)$.

\section{Patient activation}

Patient activation, as measured by the PAM, was 30.8 and 33.5 for the treatment and control groups, respectively (table 1). The treatment group's PAM score improved by 1 point to 31.8 , while the control group's mean score dropped by $<1$ point to 32.7 by the end of the study (figure 4). Neither of these changes represented a statistically significant difference in prescores and postscores for the treatment group $(\mathrm{p}=0.47)$ and control group $(p=0.55)$. Similarly, a between-group comparison did not show a statistically significant difference in score changes over the course of the study $(\mathrm{p}=0.35)$.

\section{Disease activity}

Prior to intervention activities, participants in the treatment and control groups reported a mean flare score in the previous 3 months of 1.29 out of 3 possible points, where 0 indicates (no flare) and 3 indicates (severe flare) (table 1). This is equivalent to a mild-to-moderate flare among those participants in that time period. At midintervention this score dropped to 0.83 for the treatment group, but increased back to 1.09 , postintervention. The observed 0.2 change in pre-intervention to postintervention scores was not statistically significant $(\mathrm{p}=0.66)$. The control group experienced an increasing trend in disease activity score over the course of the study, increasing to 1.62 at mid-intervention and 1.67 by the end of the study (figure 5). This change was also not statistically significant $(\mathrm{p}=0.37)$. A between-group comparison did not reach statistical significance $(p=0.35)$ for changes in scores preintervention to postintervention. Similarly, baseline mean scores for self-reported global disease activity were 4.93 for the treatment group and 5.68 for the control group, out of 10 possible points, where 10 represents the most disease activity. The mean score for the treatment group fell to $4.59(\mathrm{p}=0.75)$ while the mean score for the control group increased to $6.58(\mathrm{p}=0.38)$ (figure 6$)$. The change in score between groups was also not statistically significant $(\mathrm{p}=0.39)$.

\section{DISCUSSION}

This study sought to examine whether structured education, individualised assistance and encouragement from a lay patient navigator improved SLE patient disease selfmanagement using indicators of health literacy, lupus selfefficacy, patient activation and disease activity. Overall, the CALLS intervention improved patient activation and self-efficacy, and decreased the occurrence of lupus flares and global ratings of lupus disease activity. There was no overall change in health literacy.

The effect of the CALLS intervention on health literacy was inconsistent across the follow-up time points, which could have been due to high baseline health literacy scores in both groups, but the latter increase in mean score suggests that intervention effects may have been sustained with a longer follow-up time period. In contrast, the positive health effect on patient activation, although not statistically significant, seems as though it would have continued to diminish with a longer follow-up. This decrease may be indicative of the overall length and intensity of the intervention. The duration of the intervention (12 weeks) may have been a considerable commitment immediately following hospitalisation and may have contributed to attrition. Positive effects on self-efficacy were also not statistically significant, but the constant increasing trend suggests that intervention effects may have been sustained with a longer follow-up period. Lack of significant difference between the treatment and control group may suggest that with time, patients naturally gain self-efficacy and the intervention programme provides a minimal boost.

Although not statistically significant, we did observe a slight decrease in disease activity in the treatment group 


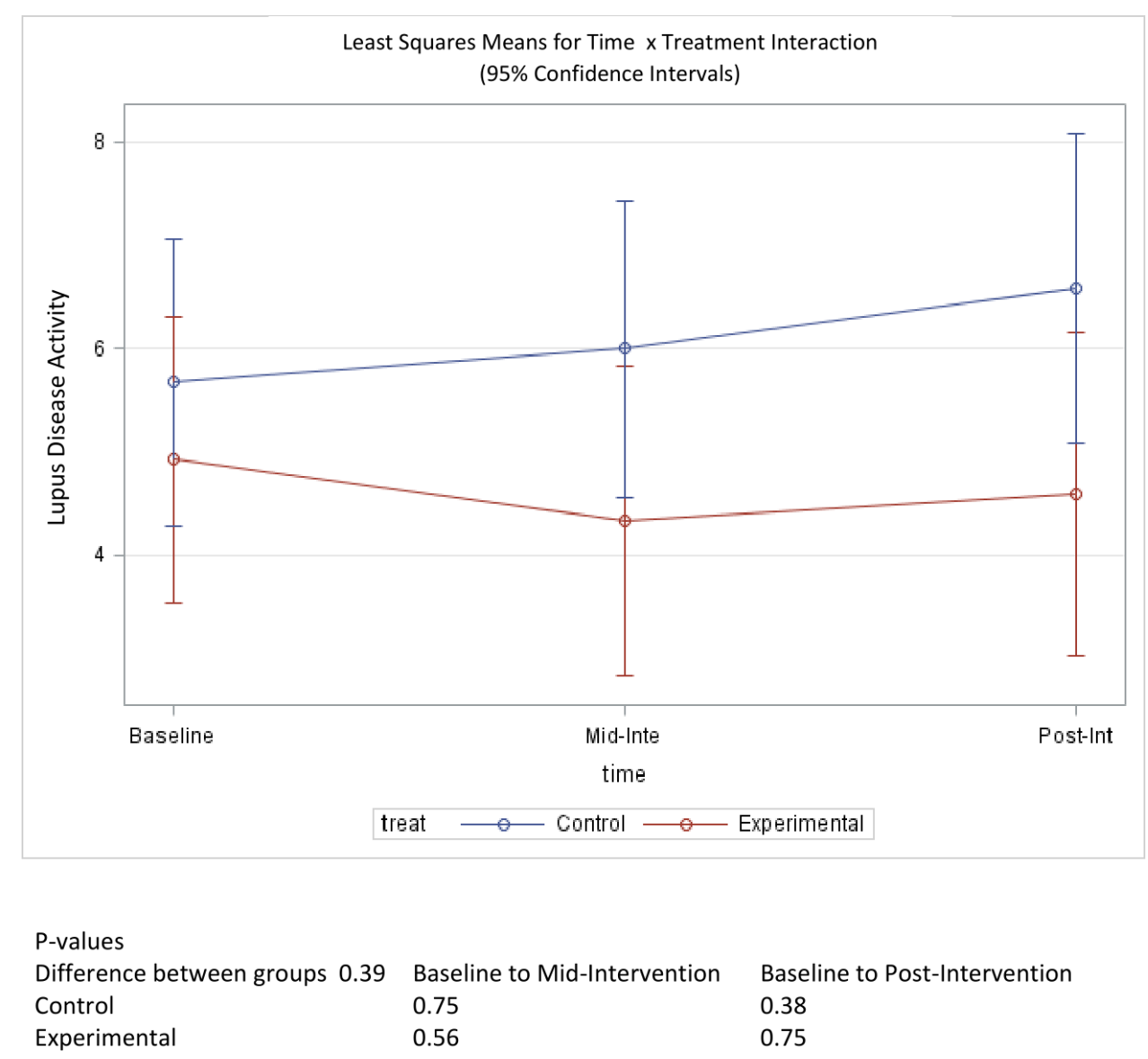

Figure 6 Mean score change of disease activity over time.

and a trend towards greater disease activity in the control group, suggesting that the patient navigation intervention was able to moderate disease activity for a short time. The observed reduction of lupus flares and overall lupus disease activity with the CALLS intervention, despite statistical insignificance, further supports our hypothesis of a brief regular telephone patient navigation intervention contributing to improved health outcomes. Thus, our findings support the availability of a patient navigator to encourage activities that promote the learning of disease self-management.

Our results agree with current literature that shows telephone-based peer support is effective and costefficient for circumventing distance barriers, allowing relative anonymity and increasing privacy, which leads to improvements in chronic disease outcomes. ${ }^{41}$ Additionally, our study recognised and implemented strategies to address commonly reported needs of persons with lupus: (1) information and support resources to help manage their illness; (2) involvement with actively engaged healthcare providers and (3) accommodating strategies for lifestyle choices to facilitate disease management. ${ }^{21}$ Our findings were inconsistent with another study that reported the impact of patient navigators to be inconclusive. ${ }^{42}$ While reported outcomes did not reach statistical significance, trends of improvement in indicators of lupus disease self-management and disease activity may be a result of the delivery of structured education by the patient navigator, since prior research has shown that selfmanagement education delivered in weekly sessions led to improvements in lupus self-efficacy, health distress and depression. ${ }^{28} 43-45$

Despite promising results, our study had some limitations. These data were self-reported, so there is the potential for socially desirable responses and recall biases. Seven participants were lost to follow-up which can also introduce selection bias. However, those seven participants were not significantly different from those who remained in the study. The generalisability of our findings is also limited by the present sample, which was primarily African- American women and drawn from a university medical centre. High baseline health literacy scores suggest that our study population has high perceived literacy with regard to health information. Data on the length of SLE disease in patients were also not collected, which could impact study findings (eg, those with lupus for 10 years may be able to better manage the disease compared with those with lupus for 6 months, which we were unable to capture). For this reason, it is possible that the results might differ if participants were recruited from other healthcare settings or we had more patient information available. Additionally, small sample size limits the power to detect differences between treatment groups, so our results may have been underpowered to accurately reflect effects of 
Table 1 Baseline demographic characteristics of CALLS control and experimental participants

\begin{tabular}{|c|c|c|}
\hline & Control $(n=16)$ & $\begin{array}{l}\text { Experimenta } \\
(n=14)\end{array}$ \\
\hline \multicolumn{3}{|l|}{ Age (years, \%) } \\
\hline $18-25$ & $1(6.7)$ & $3(21.4)$ \\
\hline $25-34$ & $3(20.0)$ & $2(14.3)$ \\
\hline $35-44$ & $5(33.3)$ & $2(14.3)$ \\
\hline $45-54$ & $1(6.7)$ & $5(35.7)$ \\
\hline $55-64$ & $3(20.0)$ & $1(7.1)$ \\
\hline$>65$ & $2(13.3)$ & $1(7.1)$ \\
\hline African- American (\%) & $13(86.7)$ & $11(78.6)$ \\
\hline \multicolumn{3}{|l|}{ Education (\%) } \\
\hline Some high school & $1(6.7)$ & $1(7.1)$ \\
\hline High school & $3(20.0)$ & $6(42.9)$ \\
\hline Some college & $6(40.0)$ & $4(28.6)$ \\
\hline College graduate & $5(33.3)$ & $3(21.4)$ \\
\hline \multicolumn{3}{|l|}{ Marriage (\%) } \\
\hline Unmarried & $1(6.7)$ & $0(0.0)$ \\
\hline Divorced & $2(13.3)$ & $2(14.3)$ \\
\hline Married & $3(20.0)$ & $3(21.4)$ \\
\hline Never married & $8(53.3)$ & $8(57.1)$ \\
\hline Separated & $1(6.7)$ & $1(7.1)$ \\
\hline \multicolumn{3}{|l|}{ Income (US\$) (\%) } \\
\hline$<15 \mathrm{~K}$ & $5(35.7)$ & $5(35.7)$ \\
\hline $15 \mathrm{~K}$ & $1(7.1)$ & $1(7.1)$ \\
\hline $20 \mathrm{~K}$ & $1(7.1)$ & $1(7.1)$ \\
\hline $25 \mathrm{~K}$ & $2(14.3)$ & $2(14.3)$ \\
\hline $30 \mathrm{~K}$ & $1(7.1)$ & $3(21.4)$ \\
\hline $40 \mathrm{~K}$ & $1(7.1)$ & $1(7.1)$ \\
\hline $60 \mathrm{~K}$ & $3(21.4)$ & $1(7.1)$ \\
\hline \multicolumn{3}{|l|}{ Employment (\%) } \\
\hline $\begin{array}{l}\text { Unemployed/ } \\
\text { Disability pay }\end{array}$ & $8(53.3)$ & $8(57.1)$ \\
\hline Working full time & $4(26.7)$ & $2(14.3)$ \\
\hline Working part time & $1(6.7)$ & $3(21.4)$ \\
\hline Retired & $2(13.3)$ & $1(7.1)$ \\
\hline \multicolumn{3}{|l|}{ Insurance (\%) } \\
\hline No health insurance & $2(13.3)$ & $1(7.1)$ \\
\hline Medicaid & $7(46.7)$ & $6(42.9)$ \\
\hline Medicare & $2(13.3)$ & $5(35.7)$ \\
\hline Private & $2(13.3)$ & $2(14.3)$ \\
\hline Other & $2(13.3)$ & $0(0.0)$ \\
\hline $\begin{array}{l}\text { Baseline health literacy } \\
\text { score (mean (SD)) }\end{array}$ & $10.33(1.72)$ & $9.57(1.60)$ \\
\hline $\begin{array}{l}\text { Baseline total patient } \\
\text { activation measure } \\
\text { (mean (SD)) }\end{array}$ & $33.50(3.98)$ & $30.79(3.40)$ \\
\hline
\end{tabular}

Continued
Table 1 Continued

\begin{tabular}{lcc} 
& Control $(\mathbf{n}=16)$ & $\begin{array}{l}\text { Experimental } \\
(\mathbf{n}=14)\end{array}$ \\
\hline $\begin{array}{l}\text { Baseline lupus flare } \\
\text { in the past } 3 \text { months } \\
\text { (mean (SD)) }\end{array}$ & $1.29(0.99)$ & $1.29(1.33)$ \\
$\begin{array}{l}\text { Baseline lupus disease } \\
\text { activity during the past }\end{array}$ & $5.68(3.18)$ & $4.93(2.27)$ \\
$\begin{array}{l}3 \text { months, on a scale } \\
\text { of 1-10 (mean (SD)) }\end{array}$ & \\
$\begin{array}{l}\text { Baseline total self- } \\
\text { efficacy (coping) score } \\
\text { (mean (SD)) }\end{array}$ & $358.87(126.91)$ & $359.86(128.11)$ \\
\hline
\end{tabular}

CALLS, Care-coordination Approach to Learning Lupus Self-Management.

the intervention, which could explain the lack of statistically significant changes from baseline to 12 months in intervention compared with control participants, for any of the outcomes examined. While randomised controlled trial study design was a notable strength of our study, a larger sample will be necessary to evaluate whether the intervention may work on further study, since a definitive statement regarding the improvement of outcomes is beyond the current data presented.

\section{CONCLUSION}

This study found that brief, regular, proactive telephone contact by a patient navigator improved patient activation, self-efficacy, lupus flares and ratings of global lupus disease activity. Even though the effects were not statistically significant, the results of this study demonstrate the potential efficacy of SLE-specific patient navigation and the potential for individually tailored educational content delivered in weekly phones sessions to improve SLE disease self-management. This suggests that a lay patient navigator integrated into the healthcare team to provide modelling and reinforcement to patients with SLE could encourage patients to engage in activities that promote the learning of disease self-management skills and support their practice of these learnt skills. This could ultimately lead to improved health-related quality of life, self-management and disease activity and associated reductions in healthcare costs.

Future research on the integration of a patient navigator to improve SLE self-management should assess long-term effects beyond 3 months, including the cost-effectiveness of a lay patient navigator for patients with SLE. Since the current study targeted inpatient admissions as a marker of failed disease self-management, a long-term investigation of the impact of patient navigation sustaining and expanding health improvements could include assessment of prevented readmissions and corresponding cost savings among different lengths of SLE disease.

Despite the proliferation of patient navigation programmes across the USA, information related to the 
economic impact and sustainability of these programmes is lacking. ${ }^{46}$ Given the success of the patient navigator approach in other chronic conditions that disproportionately impact minorities, and its responsiveness to the needs of this unique population, demonstration of a costeffective and feasible means of sustaining benefits could result in health improvements that have not been attainable with other interventions. Thus, using a patient navigator to improve the self-management of lupus among African-American women would significantly reduce disparities and have considerable public health impact.

\section{Author affiliations}

${ }^{1}$ Department of Public Health Sciences, Medical University of South Carolina, Charleston, SC, USA

${ }^{2}$ Public Health Sciences, Medical University of South Carolina, Charleston, SC, USA

${ }^{3}$ Health Economics Resource Center, VA Palo Alto, Menlo Park, CA, USA

${ }^{4}$ Medicine, Medical University of South Carolina, Charleston, SC, USA

${ }^{5}$ Medical Service, Ralph H Johnson VA Medical Center, Charleston, SC, USA

Contributors EMW was the principal investigator and JCO was a senior coinvestigator. AAW was involved in intervention development, implementation, evaluation, data analysis and manuscript writing. CLD-G, AB and TDF were involved in data analysis and manuscript writing, and VR provided statistical oversight. All authors read and approved the final version for publication.

Funding This publication was supported by the South Carolina Clinical \& Translational Research (SCTR) Institute, with an academic home at the Medical University of South Carolina CTSA, NIH/NCATS grant number UL1TR001450.

Disclaimer The contents are solely the responsibility of the authors and do not necessarily represent the official views of the NIH or NCATS.

Competing interests None declared.

Patient consent for publication Not required.

Ethics approval The study was approved by Medical University of South Carolina's Institutional Review Board. All participants provided written informed consent prior to taking part in any study related activities.

Provenance and peer review Not commissioned; externally peer reviewed.

Data availability statement Data are available on reasonable request, deidentified participant data available from corresponding author.

Supplemental material This content has been supplied by the author(s). It has not been vetted by BMJ Publishing Group Limited (BMJ) and may not have been peer-reviewed. Any opinions or recommendations discussed are solely those of the author(s) and are not endorsed by BMJ. BMJ disclaims all liability and responsibility arising from any reliance placed on the content. Where the content includes any translated material, BMJ does not warrant the accuracy and reliability of the translations (including but not limited to local regulations, clinical guidelines, terminology, drug names and drug dosages), and is not responsible for any error and/or omissions arising from translation and adaptation or otherwise.

Open access This is an open access article distributed in accordance with the Creative Commons Attribution Non Commercial (CC BY-NC 4.0) license, which permits others to distribute, remix, adapt, build upon this work non-commercially, and license their derivative works on different terms, provided the original work is properly cited, appropriate credit is given, any changes made indicated, and the use is non-commercial. See: http://creativecommons.org/licenses/by-nc/4.0/.

\section{ORCID iDs}

Jim C Oates http://orcid.org/0000-0002-5426-1359

Edith Marie Williams http://orcid.org/0000-0002-3933-3019

\section{REFERENCES}

1 Danchenko N, Satia JA, Anthony MS. Epidemiology of systemic lupus erythematosus: a comparison of worldwide disease burden. Lupus 2006;15:308-18.

2 Kan $\mathrm{HJ}$, Song X, Johnson $\mathrm{BH}$, et al. Healthcare utilization and costs of systemic lupus erythematosus in Medicaid. Biomed Res Int 2013;2013:1-8.
3 Garris C, Jhingran P, Bass D, et al. Healthcare utilization and cost of systemic lupus erythematosus in a US managed care health plan. $J$ Med Econ 2013;16:667-77.

4 Garris C, Shah M, Farrelly E. The prevalence and burden of systemic lupus erythematosus in a Medicare population: retrospective analysis of Medicare claims. Cost Eff Resour Alloc 2015;13:9.

5 Pelletier EM, Ogale S, Yu E, et al. Economic outcomes in patients diagnosed with systemic lupus erythematosus with versus without nephritis: results from an analysis of data from a US claims database. Clin Ther 2009;31:2653-64.

6 Kulczycka L, Sysa-Jedrzejowska A, Robak E. Quality of life and satisfaction with life in SLE patients-the importance of clinical manifestations. Clin Rheumatol 2010;29:991-7.

7 Jolly M. How does quality of life of patients with systemic lupus erythematosus compare with that of other common chronic illnesses? J Rheumatol 2005;32:1706-8.

8 Pons-Estel GJ, Ugarte-Gil MF, Alarcón GS. Epidemiology of systemic lupus erythematosus. Expert Rev Clin Immunol 2017;13:799-814.

9 Yen EY, Shaheen M, Woo JMP, Li N, McCurdy DK, Karlamangla A, et al. 46-Year trends in systemic lupus erythematosus mortality in the United States, 1968 to 2013: a nationwide population-based study. Ann Intern Med 2017;167:777-85.

10 Pons-Estel GJ, Alarcón GS, Scofield L, et al. Understanding the epidemiology and progression of systemic lupus erythematosus. Semin Arthritis Rheum 2010;39:257-68.

11 Fernández M, Alarcón GS, Calvo-Alén J, et al. A multiethnic, multicenter cohort of patients with systemic lupus erythematosus (SLE) as a model for the study of ethnic disparities in SLE. Arthritis Rheum 2007;57:576-84.

12 Lawrence RC, Helmick CG, Arnett FC, et al. Estimates of the prevalence of arthritis and selected musculoskeletal disorders in the United States. Arthritis Rheum 1998;41:778-99.

13 Hibbard JH, Stockard J, Mahoney ER, et al. Development of the patient activation measure (PAM): conceptualizing and measuring activation in patients and consumers. Health Serv Res 2004;39:1005-26.

14 Charoenwoodhipong P, Harlow SD, Marder W, et al. Dietary omega polyunsaturated fatty acid intake and patient-reported outcomes in systemic lupus erythematosus: the Michigan lupus epidemiology and surveillance program. Arthritis Care Res 2020;72:874-81.

15 Feldman $\mathrm{CH}$, Wohlfahrt A, Campos A, et al. Can patient Navigators improve adherence to disease-modifying antirheumatic drugs? quantitative findings from a six-month single-arm pilot intervention. Arthritis Care Res 2018;70:1400-5.

16 Heiman E, Lim SS, Bao G, Gaobin B, et al. Depressive symptoms are associated with low treatment adherence in African American individuals with systemic lupus erythematosus. J Clin Rheumatol 2018;24:368-74.

17 Jordan J, Thompson NJ, Dunlop-Thomas C, et al. Relationships among organ damage, social support, and depression in African American women with systemic lupus erythematosus. Lupus 2019;28:253-60.

18 Haupt M, Millen S, Jänner M, et al. Improvement of coping abilities in patients with systemic lupus erythematosus: a prospective study. Ann Rheum Dis 2005;64:1618-23.

19 Uribe AG, McGwin G, Reveille JD, et al. What have we learned from a 10-year experience with the LUMINA (lupus in minorities; nature vs. nurture) cohort? where are we heading? Autoimmun Rev 2004;3:321-9.

20 Ranaghan C, Boyle K, Meehan M, et al. Effectiveness of a patient navigator on patient satisfaction in adult patients in an ambulatory care setting. JBI Database of Systematic Reviews and Implementation Reports 2016;14:172-218.

21 Neville C, Da Costa D, Mill C, et al. The needs of persons with lupus and health care providers: a qualitative study aimed toward the development of the lupus interactive Navigator ${ }^{\mathrm{TM}}$. Lupus 2014;23:176-82.

22 Balaban RB, Galbraith AA, Burns ME, et al. A patient navigator intervention to reduce hospital readmissions among high-risk safety-net patients: a randomized controlled trial. J Gen Intern Med 2015;30:907-15.

23 Skillings LN, MacLeod D. The patient care coordinator role: an innovative delivery model for transforming acute care and improving patient outcomes. Nurs Adm Q 2009;33:296-300.

24 Solorio R, Bansal A, Comstock B, et al. Impact of a chronic care coordinator intervention on diabetes quality of care in a community health center. Health Serv Res 2015;50:730-49.

25 Heisler M. Building peer support programs to manage chronic disease: seven models for success. California HealthCare Foundation, 2006. 
26 Williams EM, Egede L, Faith T, et al. Effective self-management interventions for patients with lupus: potential impact of peer mentoring. Am J Med Sci 2017;353:580-92.

27 Williams EM, Egede L, Oates JC, et al. Peer approaches to selfmanagement (PalS): comparing a peer mentoring approach for disease self-management in African American women with lupus with a social support control: study protocol for a randomized controlled trial. Trials 2019;20:529.

28 Williams EM, Hyer JM, Viswanathan R, et al. Peer-to-peer mentoring for African American women with lupus: a feasibility pilot. Arthritis Care Res 2018;70:908-17.

29 Chew LD, Bradley KA, Boyko EJ. Brief questions to identify patients with inadequate health literacy. Fam Med 2004;36:588-94.

30 Lorig K, Chastain RL, Ung E, et al. Development and evaluation of a scale to measure perceived self-efficacy in people with arthritis. Arthritis Rheum 1989;32:37-44.

31 Wilcox S, Schoffman DE, Dowda M, et al. Psychometric properties of the 8-item English arthritis self-efficacy scale in a diverse sample. Arthritis 2014;2014:1-8.

32 Karlson EW, Daltroy LH, Rivest C, et al. Validation of a systemic lupus activity questionnaire (SLAQ) for population studies. Lupus 2003;12:280-6.

33 Kroenke K, Spitzer RL. The PHQ-9: a new depression diagnostic and severity measure. Psychiatr Ann 2002;32:509-15.

34 Kroenke K, Spitzer RL, Williams JB. The PHQ-9: validity of a brief depression severity measure. J Gen Intern Med 2001;16:606-13.

35 Spitzer RL, Kroenke K, Williams JBW, et al. A brief measure for assessing generalized anxiety disorder: the GAD-7. Arch Intern Med 2006;166:1092.

36 Stewart A, Ware J. Measuring functioning and well-being: the medical outcomes study approach. Duke University Press, 1992.

37 Webster K, Cella D, Yost K. The functional assessment of chronic illness therapy (FACIT) measurement system: properties, applications, and interpretation. Health Qual Life Outcomes 2003;1:79.

38 Toloza SMA, Jolly M, Alarcón GS. Quality-of-life measurements in multiethnic patients with systemic lupus erythematosus: crosscultural issues. Curr Rheumatol Rep 2010;12:237-49.

39 Borkovec TD, Nau SD. Credibility of analogue therapy rationales. J Behav Ther Exp Psychiatry 1972;3:257-60.

40 Cleary PD, Edgman-Levitan S, Roberts M, et al. Patients evaluate their hospital care: a national survey. Health Aff 1991;10:254-67.

41 Heisler M. Different models to mobilize peer support to improve diabetes self-management and clinical outcomes: evidence, logistics, evaluation considerations and needs for future research. Fam Pract 2010;27:i23-32.

42 Wohlfahrt A, Campos A, Iversen MD, et al. Use of rheumatologyspecific patient navigators to understand and reduce barriers to medication adherence: analysis of qualitative findings. PLoS One 2018;13:e0200886.

43 Williams EM, Penfield M, Kamen D, et al. An intervention to reduce psychosocial and biological indicators of stress in African American lupus patients: the balancing lupus experiences with stress strategies study. Open J Prev Med 2014;4:22-31.

44 Williams EM, Bruner L, Penfield M, et al. Stress and depression in relation to functional health behaviors in African American patients with systemic lupus erythematosus. Rheumatology 2014;2014:005.

45 Williams EM, Kamen D, Penfield M, et al. Stress intervention and disease in African American lupus patients: the balancing lupus experiences with stress strategies (BLESS) study. Health 2014;6:71-9.

46 Whitley E, Valverde P, Wells K, et al. Establishing common cost measures to evaluate the economic value of patient navigation programs. Cancer 2011;117:3616-23. 